\title{
ANÁLISE ARQUEOLÓGICA DO DISCURSO DOS PARTICIPANTES: CONTRIBUIÇÕES PARA A AVALIAÇÃO DO PLANO ESTADUAL DE EDUCAÇÃO NO SISTEMA PENITENCIÁRIO DO PARANÁ
}

\author{
Bruna Mayara Bonatto \\ Mary Ângela Teixeira Brandalise ${ }^{\mathrm{ii}}$
}

Resumo: O objetivo deste artigo consiste na exposição da contribuição da Análise Arqueológica do Discurso - AAD, fundamentada em Foucault (2012), no processo de avaliação do Plano Estadual de Educação no Sistema Prisional do Paraná (PARANÁ, 2012; 2015) no contexto das penitenciárias femininas de regime fechado. $\mathrm{O}$ emprego da análise arqueológica demonstra-se pertinente quando aplicado às pesquisas de avaliação de políticas educacionais centradas nos participantes ao possibilitar a aferição da influência da atuação dos sujeitos na atribuição social da política, bem como ao gerar reflexões capazes de aperfeiçoá-la de acordo com as especificidades do contexto e da população às quais se destinam, lhes atribuindo um caráter democrático.

Palavras-chave: Análise Arqueológica do Discurso; Avaliação Educacional; Avaliação de Políticas Educacionais; Educação na Prisão.

\section{ANÁLISIS ARQUEOLÓGICO DEL DISCURSO DE LOS PARTICIPANTES: CONTRIBUCIONES A LA EVALUACIÓN DEL PLANO ESTADUAL DE EDUCAÇÃO NO SISTEMA PENITENCIÁRIO DO PARANÁ}

Resumen: El objetivo de este artículo es exponer la contribución del Análisis del Discurso Arqueológico - AAD, basado en Foucault (2012), en el proceso de evaluación del Plano Estadual de Educação no Sistema Penitenciário do Paraná (PARANÁ, 2012; 2015) en el contexto de las cárceles de mujeres de régimen cerrado. El uso del análisis arqueológico resulta pertinente cuando se aplica a la investigación sobre la evaluación de políticas educativas centradas en los participantes, ya que permite evaluar la influencia del desempeño de los sujetos en la atribución social de la política, así como generar reflexiones capaces de mejorarla de acuerdo con Las especificidades del contexto y la población a la que están destinados, dándoles un carácter democrático.

Palabras clave: Análisis del discurso arqueológico; Evaluación educativa; Evaluación de políticas educativas; Educación en prisión.

\section{Introdução}

No Brasil, a Lei de Execução Penal, de 1984, já preconizava a assistência educacional do sujeito em cumprimento de pena. No entanto, a Educação na Prisão enquanto discussão e ação política no país recebeu maiores incentivos a partir de 2005 por intermédio de intervenções internacionais. Um desses incentivos ocorreu em 2011 pela parceria entre o Governo Federal e a UNESCO, por meio da cooperação interministerial entre o Ministério da Educação e o Ministério da Justiça, foi publicado o Plano Estratégico de Educação no âmbito do Sistema Prisional - PEESP (BRASIL, 2011). 
O PEESP (BRASIL, 2011) dispõe que cada estado da federação precisa elaborar e desenvolver seu próprio plano para a oferta de educação à população penitenciária. Dessa forma, em 2012, o estado do Paraná, especificamente através da Secretaria de Estado da Educação e Secretaria de Estado da Justiça e Cidadania, instituiu o Plano Estadual de Educação no Sistema Prisional do Paraná - PEESPP, que foi atualizado em 2015.

A partir do desenvolvimento destes planos estaduais é pertinente realizar suas avaliações no intuito de descobrir seus limites e possibilidades diante das demandas do contexto em que estão inseridas, bem como subsidiar suas reorientações. Concorda-se, assim, com Worthen, Sanders e Fitzpatrick (2004, p. 36) quando afirmam que a avaliação "leva a recomendações cuja meta é otimizar o objeto de avaliação em relação a seu(s) propósito(s) futuro(s)".

O objetivo deste artigo consiste na exposição da contribuição da análise arqueológica ${ }^{\mathrm{iii}}$ do discurso (AAD), fundamentada em Foucault (2012), em um processo de avaliação de políticas educacionais centrado nos participantes e orientado para/por uma agenda social, por meio da apresentação de seu emprego analítico no desenvolvimento da avaliação do PEESPP (PARANÁ, 2012; 2015) no contexto das penitenciárias femininas de regime fechado.

A pesquisa de avaliação do PEESPP (PARANÁ, 2012; 2015), de natureza qualitativa, foi realizada por meio de uma postura crítica e dialógica, fundamentada em um referencial teórico pluralista, que integra três teorias: a teoria da Avaliação; a teoria da Política; e a teoria das Ciências Sociais (FERNANDES, 2010).

Sendo assim, realizada dessa forma a AAD foi utilizada como metodologia para a análise do conteúdo coletado no processo de avaliação do PEESPP (PARANÁ, 2012; 2015), especificamente para a análise do conteúdo das entrevistas realizadas com os sujeitos de pesquisa: internas, professores, agentes e gestores das penitenciárias femininas paranaenses de regime fechado.

Neste artigo a interação teórica e prática realizada na análise arqueológica do discurso (AAD) do resultado do processo da avaliação do PEESPP (PARANÁ, 2012; 2015) é apresentada. A qual foi objeto de uma pesquisa de avaliação realizada entre os anos 2015 e 2019, como tese de doutorado em um Programa de Pós-Graduação em Educação de uma Universidade pública paranaense.

A pesquisa de avaliação teve como enfoque a etapa de implementação do PEESPP (PARANÁ, 2012; 2015). Isto é, compreender e analisar como esta política estadual de Educação na Prisão vem sendo atuada no contexto das penitenciárias femininas de regime fechado. Somente as internas em regime fechado frequentam os programas educacionais ofertados pela própria instituição penal via subsídio do PEESPP (PARANÁ, 2012; 2015). No Paraná há duas instituições para o cumprimento de pena no regime fechado, as quais constituíram o campo da pesquisa. 
Uma destas instituições optou, em 2018, por interromper a realização do estudo, sendo realizada nela uma única visita. Diante deste impasse, somente em uma instituição foi possível desenvolver todos os procedimentos de coleta de dados previstos para a investigação.

O processo de avaliação foi desenvolvido por meio dos seguintes procedimentos: a análise documental, desenvolvida por meio da arqueologia dos principais marcos normativos da Educação na Prisão na esfera supranacional, nacional e estadual; a pesquisa bibliográfica, consistindo na revisão sistemática da literatura acadêmica brasileira (teses e dissertações) que aborda a temática da Educação na Prisão; a observação, realizada pelas pesquisadoras e registradas em um diário de campo; e as coletas de dados junto aos sujeitos participantes por meio de entrevista e questionário, respectivamente, para apreensão dos dados referentes ao perfil socioeducacional dos sujeitos e dos dados sobre a avaliação do PEESPP (PARANÁ, 2012; 2015).

Somente uma dentre as duas instituições penais femininas de regime fechado do Paraná permitiu a realização da pesquisa na íntegra. A instituição que participou de todo o processo de avaliação do PEESPP por meio da investigação forneceu os relatórios acerca do perfil social e educacional das internas. Dois, dentre os três gestores da unidade, concederam entrevista e preencheram o questionário. Seis dentre os trinta e seis agentes da instituição participaram da investigação. Dos sete educadores (professores) que exerciam docência na unidade, seis participaram da investigação. Dez internas foram autorizadas a participarem da pesquisa, pela instituição. Os instrumentos de coletas de dados junto aos sujeitos de pesquisa foram elaborados para compreender cinco aspectos relevantes acerca da política em avaliação: dados socioeducacionais, objetivo do PEESPP, infraestrutura, atuação profissional e diversidade e gênero.

A pesquisa foi realizada por meio da abordagem crítica e dialógica de avaliação, pela análise qualitativa dos dados, centrada nos participantes e orientada por/para uma agenda social. Esta postura epistemetodológica foi elencada na avaliação do PEESPP (PARANÁ, 2012; 2015) pelo potencial de indicar as possibilidades e limitações das ações do Plano no contexto da prática em instituições penitenciárias para a população feminina.

Cabe mencionar que o projeto de pesquisa foi encaminhado ao Comitê de Ética por meio da Plataforma Brasil, obtendo parecer favorável ao seu desenvolvimento (CEP 3.234.260).

Neste trabalho expõe-se como a AAD foi aplicada à análise do conteúdo dos depoimentos obtidos por meio das entrevistas e, também, na análise documental, no intuito de demonstrar a forma como Foucault (2012) pode contribuir no desenvolvimento de uma pesquisa no âmbito da avaliação de políticas educacionais. Por esse motivo, apresentou-se, sumariamente, o contexto de desenvolvimento da pesquisa de avaliação e, a seguir, expõe-se a forma como a AAD foi nela aplicada. 
Avaliação de políticas educacionais centrada nos participantes: a interação entre os contextos, os sujeitos e os discursos

As Ciências Humanas contribuíram para a constituição da avaliação como campo científico. Foram elas que possibilitaram uma redistribuição da episteme ao instituírem o homem enquanto um objeto científico, por meio da apropriação da formalização matemática para afirmar sua positividade científica (FOUCAULT, 1995).

Pela análise da trajetória do desenvolvimento do campo teórico da Avaliação Educacional, compreende-se que a Avaliação teve sua origem aos moldes do paradigma positivista, orientando suas práticas na forma de exames, os quais produziam mensurações. Tal cultura de avaliação emergiu das práticas escolares, dos quartéis e dos hospitais que empregavam esse mesmo paradigma para classificar e sancionar os sujeitos, produzindo um controle normalizante (FOUCAULT, 1999).

Desde então, o campo da Avaliação Educacional acompanhou o aprimoramento e o surgimento de novos paradigmas nas Ciências Humanas que possibilitaram um distanciamento das origens positivistas, havendo atualmente a possibilidade de práticas pautadas em um paradigma dialético e crítico ${ }^{\text {iv }}$, fundamentado em teorias construtivistas (MACHADO, 2013).

Concebendo como definição de política pública o conjunto de decisões tomadas pelas instituições de Estado com o intuito de solucionar um problema que emerge do contexto de sua atribuição, entende-se que o campo da pesquisa sobre políticas é complexo e cada vez mais amplo (MAINARDES, 2018). Neste campo, as políticas públicas correspondem a um dos objetos de avaliação, sejam em nível federal, estadual ou municipal.

A literatura especializada salienta que ao abordar em um estudo de avaliação uma política como objeto, logo se verifica que ela tem atribuições mais amplas do que aquelas citadas discursivamente em documentos, pois estão vinculadas a outras políticas e instituições sociais. Assim, o pesquisador precisará dispensar esforços na elaboração de conceitos e metodologias de avaliação condizentes com a realidade na qual ela (a política) se insere.

A esse respeito deixa-se explícita a compreensão da política, do saber/fazer política em âmbito educacional, como um processo dinâmico, fluído, cientes de que não se trata de um "processo hiper-racional e linear" (MAINARDES, 2015, p. 165). A partir desta concepção, o objetivo da avaliação de uma dada política educacional não é encontrar suas falhas e/ou resultados enquanto praticada, nem ao menos a responsabilização - seja ela positiva por meio de bonificação ou negativa por meio de punições (AFONSO, 2014) -, mas sim apontar suas "contribuições - positivas e negativas - para a realização da justiça social” (MAINARDES; MARCONDES, 2009, p. 304). 
A avaliação significa a determinação do valor, da qualidade, do mérito de algo que, neste estudo, se refere à qualidade da política de Educação na Prisão no contexto paranaense. Compreende-se que esta política se caracteriza como “textos e 'coisas' (legislação e estratégias nacionais), mas também como processos discursivos que são complexamente configurados, contextualmente mediados e institucionalmente prestados" (BALL; MAGUIRE; BRAUN, 2016, p. 13). Neste sentido, a avaliação da política de Educação na Prisão do Estado do Paraná constitui-se como um instrumento necessário para a compreensão e/ou a (re)orientação das ações por elas subsidiadas.

Ante a complexidade do objeto de avaliação - o PEESPP (PARANÁ, 2012; 2015) -, se fez necessário para a materialização da pesquisa de avaliação o emprego de uma perspectiva teórica pluralista que articula os autores do campo da avaliação de políticas educacionais e a análise arqueológica do discurso (AAD) conforme os pressupostos de Foucault (2012). Esse referencial teórico foi assim organizado diante da consciência da necessidade de um modelo analítico que possibilitasse a execução de uma pesquisa de avaliação de política educacional em uma perspectiva crítica de forma relacional e reflexiva.

Esta opção se deve, também, à compreensão da atribuição das políticas educacionais em nível macro e microssociológico ${ }^{\mathrm{v}}$, respectivamente, para a sociedade contemporânea e para a atribuição pedagógica que se deu à execução das penas, o que gerou a instituição de escolas dentro das penitenciárias.

Ao considerar que a complexidade da transformação histórica culminou em mudanças no campo econômico, jurídico-político e científico, compreende-se que a atribuição pedagógica das penas emergiu da formação de uma sociedade disciplinar (FOUCAULT, 1999). Neste contexto, as políticas educacionais têm a finalidade formal de generalizar igualmente o direito à educação, ao mesmo tempo em que exerce um controle social e, sendo assim, compõem a forma jurídica geral que no contexto da prática interage com seus atores garantindo um sistema de direitos,

[...] sustentada por esses mecanismos miúdos, cotidianos e físicos, por todos esses sistemas de micropoder essencialmente inigualitários e assimétricos que constituem as disciplinas. E se, de uma maneira formal, o regime representativo permite que direta ou indiretamente, com ou sem revezamento, a vontade de todos forma a instância fundamental da soberania, as disciplinas dão, na base, garantia da submissão das forças e dos corpos (FOUCAULT, 1999, p. 194-195).

Na extensão do direito à educação à população penitenciária a escola enquanto instituição é alocada dentro de outra instituição, a penitenciária, sendo possível perceber, na interação entre as duas instituições, como a escola é importante no processo disciplinar e como essa atribuição disciplinar se torna mais forte, mais robusta, quando associada à atribuição disciplinar da instituição penal.

Para melhor entendimento desta relação interinstitucional e de sua atribuição, tendências e influências na conjuntura social, destaca-se que "o importante na ideia de sociedade disciplinar é a ideia de 
sociedade: as disciplinas fazem a sociedade; criam uma espécie de linguagem comum entre todo o gênero de instituições; tornam-se traduzíveis umas nas outras" (EWALD, 1993, p. 83).

As políticas se constituem como um solo positivo, seus discursos constituem-se como subsídios de ações, portanto são tomados como verdade, legitimadas como um saber (FOUCAULT, 2012). A partir da publicação de uma política seus discursos serão apropriados pelos sujeitos que irão interpretar e atuar suas disposições no contexto da prática. Por meio da apropriação dos pressupostos teóricos de Foucault no processo de avaliação é possível uma descrição e análise comparada das formações discursivas a respeito do PEESPP (PARANÁ, 2012; 2015).

Diante do exposto, na análise documental da pesquisa foram apreciados os documentos oficiais que instituem e fundamentam a Educação na Prisão em nível global, federal, estadual e institucional, sendo um deles, em especial, o objeto de avaliação, o PEESPP (PARANÁ, 2012; 2015). Para esta análise, considerando os pressupostos da arqueologia do saber de Foucault (2012), compreende-se e considera-se a política tanto enquanto texto, como enquanto discurso.

Enquanto texto, como bem explica Mainardes (2009), a política é compreendida na sua multiplicidade de leituras que emergem da dinâmica social dos leitores, que também tem como característica a diversidade. $\mathrm{Na}$ arena da disputa de influências, no âmbito do Estado, somente alguns interesses são legitimados "e apenas algumas vozes são ouvidas” (MAINARDES, 2009, p. 53).

Enquanto discurso, as palavras empregadas são dotadas e imbuídas por significados que possibilitam a construção de pensamentos. Assim, a política como discurso constitui-se como o meio pelo qual se delimita o horizonte da verdade a ser prestigiada, bem como pelo qual se distribuem as vozes (MAINARDES, 2009). Ou seja, enquanto discurso, haverá vozes legitimadas, de maior prestígio por serem consideradas como verdade e em oposição haverá as vozes marginalizadas, que não serão ouvidas ou que serão consideradas como inverdades.

Dessa forma, esses conceitos são complementares e denotam o exercício das relações de poder "ao passo que a política como discurso enfatiza os limites impostos pelo próprio discurso, a política como texto enfatiza o controle que está nas mãos dos leitores" (MAINARDES, 2009, p. 64).

Neste sentido, é possível compreender nas formações discursivas presentes no PEESPP (PARANÁ, 2012; 2015), bem como naquelas oriundas do seu contexto da prática, uma ordem estabelecida na compreensão das questões acerca do acesso à educação em penitenciárias femininas de regime fechado, por meio dos pressupostos foucaultianos, a "análise da possibilidade da ordem, da positividade histórica, a partir da qual um saber pode se constituir, a partir do qual teorias e conhecimentos, reflexões e ideias são possíveis. E é nesse espaço de ordem que o saber se constitui” (ARAÚJO, 2007, p. 04-05).

A apropriação da análise arqueológica de Foucault contribui com o desenvolvimento da avaliação fundamentada nos princípios da abordagem de avaliação orientada por/para uma agenda social 
considerando a importância e a relevância das formações discursivas, ou a ausência delas, na avaliação do PEESPP (PARANÁ, 2012; 2015). Este referencial se mostra apropriado uma vez que a análise de cada contexto da política demanda uma reflexão acerca das formações discursivas.

A análise arqueológica torna possível encontrar a ordem da formação discursiva a respeito do acesso à educação nos principais marcos normativos federais para a Educação na Prisão brasileira, que deram abertura à origem do discurso normativo paranaense a respeito da extensão do direito à educação à população penitenciária. Ela permite também compreender qual o grau de importância dado à avaliação das próprias ações subsidiadas por estes marcos normativos.

A arqueologia, de acordo com Foucault (2012, p. 49), corresponde ao "balizamento e à descrição dos tipos de discurso". Isto significa que o "termo 'arqueologia' remete, então, ao tipo de pesquisa que se dedica a extrair os acontecimentos discursivos como se eles estivessem registrados em um arquivo" (FOUCAULT, 2012, p. 257). Assim sendo, a arqueologia é responsável pelo mapeamento da formação histórica dos discursos e a apresentação da ordem que eles exprimem.

Nessa perspectiva, pelo processo de avaliação, compreende-se a formação histórica do discurso a respeito do acesso à educação presente no PEESPP (PARANÁ, 2012; 2015). Isto é, como esse discurso surgiu e se formou enquanto um discurso legitimado sobre a garantia do acesso à educação no âmbito penitenciário do Paraná. Já no contexto da prática da política, será possível avançar na análise dessas formações discursivas uma vez que os sujeitos que interpretam e atuam a política imprimem em suas ações seus próprios valores, cindidos pelas suas próprias experiências profissionais e de vida, participando também na reprodução ou na reestruturação da ordem dos discursos a respeito do acesso à educação em uma instituição penal.

Esta análise é pertinente pela possibilidade de compreensão da ordem do discurso que revela a interação entre as instituições e os sujeitos que atuam a política em seus diferentes contextos. De acordo com Foucault (2012), na arqueologia há uma normatividade, uma ordem do discurso que revela uma inserção histórica e social. A análise do discurso a respeito do acesso à educação presente no PEESPP (PARANÁ, 2012; 2015), bem como a análise dos discursos dos sujeitos que o desenvolvem, permitem: a compreensão de sua formação histórica; as influências do e no campo social; sua trajetória e suas tendências em sua constituição no decorrer do período de sua formação e publicação; e sua materialização no contexto da prática.

Ao compreender a atribuição disciplinar da política de Educação na Prisão na conjuntura social enquanto uma ação do Estado, no sentido de estender o acesso à educação à população penitenciária, o processo de avaliação pretende compreender como este objetivo da política se materializa no contexto da prática nas penitenciárias femininas de regime fechado do Paraná. 
A avaliação do PEESPP (PARANÁ, 2012; 2015) centrou-se nos participantes, isto é, nos sujeitos que praticam a política no contexto das penitenciárias femininas de regime fechado. De acordo com Worthen, Sanders e Fitzpatrick (2004), a avaliação centrada nos participantes emergiu da crítica às abordagens de avaliação orientadas pelo paradigma objetivista. Essa proposta distancia-se da preocupação em definir e classificar objetivos, por meio da sofisticação técnica dos sistemas de avaliação. Ela almeja o real conhecimento dos fenômenos que avalia por meio da reflexão da complexidade do elemento humano na atuação de uma política.

Por meio desta abordagem, adota-se uma postura dialógica e crítica, na qual os diferentes sujeitos que atuam a política são co-participantes do processo de avaliação. Além disso, a reflexão junto aos participantes a respeito das ações e do ambiente da política também é relevante, ao passo que possibilitam identificar os limites e as possibilidades da atuação da política gerando uma análise do contexto da prática da política orientada por/para uma agenda social (FERNANDES, 2018). Por meio da avaliação centrada nos participantes,

o avaliador descreve os diferentes valores e necessidades dos indivíduos e grupos atendidos pelo programa pesando e ponderando essa pluralidade de julgamentos e critérios de uma forma intuitiva em grande parte [...]. O que é julgado "melhor" depende muito dos valores e perspectivas do que quer que seja que os grupos ou indivíduos estejam julgando (WORTHEN, SANDERS, FITZPATRICK, 2004, p. 224-225).

Ainda em acordo com as disposições de Worthen, Sanders e Fitzpatrick (2004), a compreensão de um problema, processo ou evento acerca da política em avaliação deriva da observação e das descobertas realizadas no ambiente da atuação da política e não se caracteriza como o produto de um plano de estudo determinado antes de se realizar a avaliação. Sendo assim, durante o processo de avaliação centrada nos participantes se adotam múltiplas fontes e tipos de dados acerca da política como, por exemplo, os sujeitos, os documentos, os dados quantitativos e os qualitativos.

Dessa forma, o processo de avaliação não segue um plano padronizado, ele avança em função da participação dos sujeitos, na compreensão da totalidade e/ou de algum aspecto do objeto avaliado - a política. Sendo assim, havendo uma diversidade de indivíduos participantes do processo de avaliação, há também diferentes discursos acerca da política, os quais correspondem às próprias perspectivas de cada sujeito, oriundas da experiência própria de cada um naquele mesmo contexto, trabalhando-se com a representação de realidades múltiplas.

Apesar das diferentes perspectivas dos sujeitos, todas são consideradas e aceitas sem que nenhuma represente a verdade de modo absoluto. Todos os discursos são relevantes à realização da avaliação, considerando a complexidade da atuação da política (WORTHEN, SANDERS, FITZPATRICK, 2004). 
As entrevistas concedidas pelos professores, pelos gestores, agentes e internas participantes da pesquisa, foram analisadas no intuito de identificar as formações discursivas a respeito do PEESPP (PARANÁ, 2012; 2015). Foram delimitados três eixos relevantes acerca do objeto avaliado na construção dos roteiros de entrevista utilizados: o objetivo do PEESPP; a atuação profissional; e a diversidade e gênero.

A abordagem da AAD aplicada ao processo de avaliação centrado nos participantes e orientado por/para uma agenda social possibilita aferir a trajetória da política de Educação na Prisão e seu potencial na promoção da equidade social no acesso à educação, uma vez que o perfil social e educacional dos sujeitos de pesquisa também foi levantado para delinear o lugar de fala dos participantes.

Em 1969, Foucault publicou o método arqueológico no livro “A Arqueologia do Saber”. Na arqueologia há uma normatividade, uma ordem, do discurso que revela uma inserção histórica e social. Assim sendo, a arqueologia é responsável pelo mapeamento da formação histórica dos discursos e a apresentação da ordem que eles exprimem.

O método arqueológico distancia-se dos paradigmas da história das ideias, propondo uma história feita por meio das descontinuidades e não mais por meio da descrição linear dos fatos. Dessa forma, o método privilegia uma constituição dos saberes por meio das inter-relações discursivas e sua interação com as instituições no intuito de revelar como os saberes aparecem e se transformam. O método centra-se no discurso real, pronunciado e concebido como materialidade, e tem como principais objetos o discurso, o enunciado e o saber. Assim, por meio de um novo método para a história, Foucault inaugurou uma nova história:

[...] em nossos dias, a história é o que transforma documentos em monumentos e que desdobra, onde se decifravam rastros deixados pelos homens, onde se tentava reconhecer em profundidade o que tinham sido, uma massa de elementos que devem ser isolados, agrupados, tornados pertinentes, inter-relacionados, organizados em conjuntos. Havia um tempo em que a arqueologia, como disciplina dos monumentos mudos, dos rastros inertes, dos objetos sem contexto e das coisas deixadas pelo passado, se voltava para a história e só tomava sentido pelo restabelecimento de um discurso histórico; que poderíamos dizer, jogando um pouco com as palavras, que a história, em nossos dias, se volta para a arqueologia - para a descrição intrínseca do monumento (FOUCAULT, 2012, p. 08).

Foucault (2012) tece uma crítica sobre a unidade, a continuidade, a totalidade e a origem, que consistem nos grandes temas da história das ideias, para diferenciá-la da análise arqueológica. Segundo ele, a arqueologia pretende definir os discursos enquanto ações em função de regras e não as representações, os pensamentos, ocultos ou manifestados nos discursos, foco da história das ideias. Assim, ele concebe o discurso como monumento, não enquanto um documento, preocupando-se não com sua transição contínua e sim com a especificidade de cada discurso, expondo a qual jogo de regras se submete, bem como se 
submete, definindo os tipos e as regras de práticas discursivas, possibilitando uma descrição sistemática de um discurso enquanto objeto. Como bem explicam Azevedo e Ramos (2003):

A arqueologia pode ser definida como uma reescrita daquilo que já foi escrito, é a descrição sistemática de um discurso-objeto. O arqueólogo não reivindica a constituição do fenômeno que ele está estudando através de sua atividade significante interessada. Ele tem, antes, que compartilhar do contexto cotidiano do discurso por ele estudado a fim de participar de sua disciplina. Deve estar ao mesmo tempo dentro e fora dos discursos que ele analisa, compartilhando da falta de significado enquanto em suspenso, esta é a condição inelutável do arqueólogo (AZEVEDO; RAMOS, 2003, p. 289).

Nesta perspectiva de análise, o discurso dos sujeitos é elevado à qualidade de acontecimento. Como o próprio ser humano consiste em um ser discursivo, construído pela própria linguagem, o seu discurso é concebido enquanto uma realidade discursiva. O método arqueológico possibilita esclarecer como a existência é construída pelo próprio homem, considerando que os sujeitos e os objetos são construídos discursivamente por meio do que se fala a respeito deles.

Para exemplificar, considerando o campo da Avaliação Educacional, sabendo que o ato de avaliar é um comportamento básico do ser humano, com atribuições desde o homem de Neanderthal (WORTHEN, SANDERS, FITZPATRICK, 2004), a avaliação formal só passou a existir a partir do momento em que foi sistematizada e enunciada enquanto tal, existindo hoje enquanto campo do conhecimento por meio do discurso acerca de suas práticas, que assim a circunscreve na história. O corpo é outro exemplo, passou a existir na modernidade com o desenvolvimento da patologia. A partir de então a medicina orientou práticas e dizeres sobre o corpo, caracterizando-o como um conjunto de órgãos.

Diante do exposto, a AAD apresentou-se como possibilidade metodológica na apreensão da dinâmica na relação entre o contexto, a política e os sujeitos à medida que desnuda a ordem do discurso dos sujeitos que participaram do processo de avaliação do PEESPP (PARANÁ, 2012; 2015).

\section{A AAD na avaliação de políticas educacionais centrada nos participantes: aspectos conceituais para análise do discurso fundamentada em Foucault}

O método arqueológico tem como conceitos principais o discurso, a prática discursiva, o enunciado, a formação discursiva e o saber. O discurso é definido por Foucault (2012, p. 132) como "um conjunto de enunciados, na medida em que se apoiem na mesma formação discursiva". O discurso é

[...] histórico - fragmento de história, unidade e descontinuidade na própria história, que coloca o problema de seus próprios limites, de seus cortes, de suas transformações, dos modos específicos de sua temporalidade, e não de seu 
surgimento abrupto em meio às cumplicidades do tempo (FOUCAULT, 2012, p. 133).

Compreende-se que os discursos, além de históricos, são influenciados pelo contexto institucional, que permite ou não que sejam explicitados. Tendo como exemplo o campo da Avaliação Educacional, um sujeito enquanto avaliador irá expressar enunciados em coerência com o campo discursivo da Avaliação Educacional em acordo com os interesses contextuais momentâneos. O discurso, portanto, consiste em uma prática que tem seus sentidos construídos por meio das relações e dos enunciados durante sua aplicação e/ou uso. Em função disto, a definição de prática discursiva consiste em um

[...] conjunto de regras anônimas, históricas, sempre determinadas no tempo e no espaço, que definiram, em uma dada época e para uma determinada área social, econômica, geográfica ou linguística, as condições de exercício da função enunciativa (FOUCAULT, 2012, p. 133).

Desse modo, a prática discursiva consiste na relação estabelecida entre o discurso e os níveis materiais do contexto. Por esse caráter a análise arqueológica permite delimitar as regras de formação dos discursos-objetos, bem como dos enunciados, no intuito de mostrar a positividade que o caracteriza, não a positividade de uma ciência, mas um saber. Assim, “os saberes são, em muitos momentos, independentes das ciências, já que encontram suas regras de formação nos mais variados campos discursivos; entretanto todas as ciências se localizam em campos do saber" (MACHADO, 1981, p. 154).

Para Foucault, o enunciado consiste em uma proposição estruturada que pode se constituir como uma unidade, ao passo que no espaço e no tempo exprimem algum conteúdo concreto. Em relação a este conceito se faz necessário distinguir o enunciado de uma enunciação: o enunciado se caracteriza pela sua possibilidade de repetição; já uma enunciação corresponde a uma frase emitida, mas que não é passível de repetição. Diferente da enunciação, “o enunciado depende de uma materialidade, que é sempre de ordem institucional, no sentido de uma estrutura de poder”, explica Machado (1981, p. 151-152).

A formação discursiva, na definição de Foucault (2012):

No caso em que se puder descrever, entre um certo número de enunciados, semelhante sistema de dispersão, e no caso em que entre os objetos, os tipos de enunciação, os conceitos, as escolhas temáticas, se puder definir uma regularidade (uma ordem, correlações, posições e funcionamentos, transformações), diremos, por convenção, que se trata de uma formação discursiva (FOUCAULT, 2012, p. 43).

Pela AAD é possível encontrar as regularidades na dispersão dos enunciados, sejam essas dispersões a respeito de semelhanças como também de diferença, pois estas regularidades consistem nos produtos do 
processo de formação discursiva. A principal característica na construção de um discurso é que ele emerge sempre de um sistema de relações, seja entre objetos, conceitos, estratégias, dentre outros.

A respeito do saber, Foucault (2012) afirma que há uma positividade em toda forma de saber e que ela não está condicionada a cientificidade, só podendo ser julgada por uma referência que seja o próprio saber. O método arqueológico tem como objetivo expor a ordem interna que constitui um determinado saber por meio dos discursos.

Diante do exposto, no contexto da avaliação do PEESPP (PARANÁ, 2012; 2015), o objetivo de realizar uma $\mathrm{AAD}$ é o de desvelar a formação discursiva a respeito da extensão do direito à educação subsidiada pelo Plano à população penitenciária feminina paranaense que cumpre pena em regime fechado. Essa análise do discurso permite a compreensão da formação histórica, bem como das influências do e no campo social, da trajetória e das tendências na constituição do Plano no decorrer do tempo em que está em execução.

Acredita-se que por meio deste referencial analítico, além de materializar os objetivos propostos pelo processo de avaliação centrado nos participantes e orientado por/para uma agenda social, é apontada a possibilidade de gerar novos debates teóricos a respeito da realidade social desvendada.

É preciso estar pronto para acolher cada momento do discurso em sua irrupção de acontecimentos, nessa pontualidade em que aparece e nessa dispersão temporal que lhe permite ser repetido, sabido, esquecido, transformado, apagado até nos menores traços, escondido bem longe de todos os olhares, na poeira dos livros. Não é preciso remeter o discurso à longínqua presença da origem; é preciso tratá-lo no jogo de sua instância (FOUCAULT, 2012, p. 31).

A AAD possibilita a compreensão das regras das formações discursivas dos sujeitos de pesquisa indicando quais relações, tendências e hierarquias são exercidas e que possibilitam, ou não, a dispersão de um dado discurso, não sendo possível outro. Como orienta Foucault (2012):

Não se trata de reencontrar o que poderia tornar legítima uma assertiva, mas isolar as condições de emergência dos enunciados, a lei de sua coexistência com outros, a forma específica de seu modo de ser, os princípios segundo os quais subsistem, se transformam e desaparecem (FOUCAULT, 2012, p. 155).

É importante destacar que as formações discursivas não correspondem ao sinônimo de representações. Como explica o autor:

A análise do pensamento é sempre alegórica em relação ao discurso que utiliza. Sua questão, infalivelmente, é: o que se dizia no que estava dito? A análise do campo discursivo é orientada de forma inteiramente diferente; trata-se de compreender o enunciado na estreiteza e singularidade de sua situação; de determinar as condições de sua existência, de fixar seus limites da forma mais justa, de estabelecer suas correlações com os outros enunciados a que pode estar ligado, de mostrar que outras 
formas de enunciação exclui. Não se busca, sob o que está manifesto, a conversa semi-silenciosa de um outro discurso: deve-se mostrar por que não poderia ser outro, como exclui qualquer outro, como ocupa, no meio dos outros e relacionado a eles, um lugar que nenhum outro poderia ocupar. A questão pertinente a uma tal análise poderia ser assim formulada: que singular existência é esta que vem à tona no que se diz e em nenhuma outra parte? (FOUCAULT, 2012, p.34).

Compreende-se que a AAD almeja revelar as condições de enunciação dos discursos, o contexto que o elege como um discurso verdadeiro, e não "a manifestação, majestosamente desenvolvida, de um sujeito que pensa, que conhece e que o diz" (FOUCAULT, 2012, p. 66). Dessa forma, a AAD:

[...] consiste em não mais tratar os discursos como conjuntos de signos (elementos significantes que remetem a conteúdos ou a representações), mas como práticas que formam sistematicamente os objetos de que falam. Certamente os discursos são feitos de signos; mas o que fazem é mais que utilizar esses signos para designar coisas. É esse mais que os torna irredutíveis à língua e ao ato da fala. É esse 'mais' que é preciso fazer aparecer e que é preciso descrever (FOUCAULT, 2012, p. 60, grifo do autor).

Nesta perspectiva, para o desenvolvimento da AAD se faz necessária a descrição dos contextos da avaliação, das políticas e dos marcos normativos que subsidiam a Educação na Prisão no Brasil e dos sujeitos que desenvolvem o PEESPP (PARANÁ, 2012; 2015). Tais contextualizações possibilitaram expor quem são e o lugar de fala dos sujeitos: de quais contextos, de quais qualidades de interação, de quais regras emergem os discursos a respeito da atuação de uma política estadual de Educação na Prisão, especificamente em instituições penais para a população feminina.

Esta contextualização evidencia formações discursivas que emergem de interações, que se submetem a regras, que ao mesmo tempo em que estão sujeitadas ao universal estão também ao específico e assim possibilitam a construção de um saber acerca da atuação do PEESPP (PARANÁ, 2012; 2015), denotando sua atribuição social.

Por meio da AAD é possível descrever, de modo sistematizado, as ordens do discurso escavado em suas especificidades, organizando-as de acordo com o nível de existência do enunciado. Dessa forma, expõem-se os enunciados que não estavam tão visíveis, apesar de presentes no discurso, compreendem-se as articulações entre os signos, identificam-se as regularidades e as dispersões, as regras que possibilitaram que as coisas fossem ditas como se apresentam, identificam-se os domínios do conhecimento, isto é, descreve-se a ordem do discurso em análise. Foucault (2012) orienta:

Descrever um enunciado não significa isolar e caracterizar um segmento horizontal, mas definir as condições nas quais se realizou a função que deu a uma série de signos (não sendo esta forçosamente gramatical nem logicamente estruturada) uma existência, e uma existência específica (FOUCAULT, 2012, p. 132-133). 
Os enunciados compõem o discurso e este último, de acordo com o autor, não se limita a uma mera organização de palavras e sim se caracteriza como o "conjunto de enunciados que se apoia em uma mesma formação discursiva" (FOUCAULT, 2012, p. 131). Sendo assim, o discurso se constitui por meio de enunciados e estes últimos são compostos por um conjunto de signos.

O signo compõe o discurso por meio dos enunciados, mas nem sempre o signo é discursivo. Não se pode compreender o signo como sinônimo de um elemento de uma língua. Isso porque uma série de signos se tornará enunciado com a condição de que tenha com “"outra coisa' [...] uma relação específica que se refira a ela mesma - e não à sua causa, nem a seus elementos" (FOUCAULT, 2012, p. 107). Isto é, o signo discursivo precisa de um referente que lhe confere uma forma de interação singular entre o enunciado e o que se enuncia.

O enunciado, portanto, consiste na modalidade da existência de um conjunto de signos. Como explica Foucault (2012), é esta modalidade

[...] que lhe permite ser algo diferente de uma série de traços, algo diferente de uma sucessão de marcas em uma substância, algo diferente de um objeto qualquer fabricado por um ser humano; modalidade que lhe permite estar em relação com um domínio de objetos, prescrever uma posição definida a qualquer sujeito possível, estar situado entre outras performances verbais, estar dotado, enfim, de uma materialidade repetível (FOUCAULT, 2012, p. 130-131).

Compreende-se que o enunciado não corresponde ao sinônimo de frase, de proposição ou de ato de fala. Todos os quatro correspondem a categorias distintas, com suas particularidades, das quais as diferem. Foucault (2012) esclarece que o enunciado está para o discurso assim como a frase está para a gramática, como a proposição está para a lógica, como o ato de fala está para uma análise. O enunciado apresenta-se por meio de séries de signos que se submetem a determinadas regras e apresentam-se enquanto uma materialidade repetível (FOUCAULT, 2012).

Os discursos, além de históricos, são influenciados pelo contexto institucional, o qual permite ou não que sejam declarados. Sendo assim, a prática discursiva consiste na relação estabelecida entre o discurso e os níveis materiais do contexto.

"Considerando o papel que as perspectivas de avaliação orientadas por/para uma agenda social podem desempenhar na qualidade das avaliações e na transformação e na melhoria da sociedade" (FERNANDES, 2018, p. 49), por meio da AAD das entrevistas oriundas do processo de avaliação é possível esclarecer a relevância social do Plano paranaense. Esta feita,

[...] pode contribuir para que a qualidade da política pública seja conhecida e discutida por setores mais ou menos alargados da sociedade. [...] geram a base empírica para que se possa discutir fundamentadamente uma dada política pública. 
[...] surge associada à distribuição de poder pois pode determinar quem ganha o quê, quando e como (FERNANDES, 2018, p. 54).

Nesta perspectiva, a avaliação não produz resultados exatos, definitivos. No entanto, permite discernir a respeito da qualidade do PEESPP (PARANÁ, 2012; 2015) ao fundamentar-se em critérios que envolvem a prática e a experiência dos sujeitos, o que lhe confere rigor e credibilidade, sendo socialmente útil para a melhoria de suas ações e de sua capacidade de sanar uma demanda social (FERNANDES, 2018). Cabe destacar que a garantia da credibilidade de uma avaliação de política educacional é compatível com a influência que exercem no âmbito político e social quando orientadas para sua melhoria e para alargar a democracia.

Os procedimentos metodológicos da AAD consistem em três momentos: o mapeamento, as escavações e a análise descritiva. No mapeamento se elencam as fontes de análises, que no contexto da avaliação apresentada correspondem ao conteúdo: dos planos federal e estadual para a Educação na Prisão; de estatísticas do InfoPen ${ }^{\text {vi }}$; dos questionários; e das entrevistas. As escavações consistem na leitura e análise das fontes mapeadas no intuito de expor os enunciados relevantes dentre todo o conteúdo das fontes. Por fim, a análise descritiva se caracteriza como o produto da investigação, pois compreende a descrição sistematizada do discurso escavado (COUTINHO; CARLOS, 2014).

Após o desenvolvimento destes três momentos na análise dos dados coletados junto aos sujeitos que participaram do processo de avaliação do PEESPP (PARANÁ, 2012; 2015), foi possível desnudar a ordem dos discursos. Eles possibilitaram a reflexão acerca dos limites e das possibilidades do Plano paranaense no contexto das penitenciárias femininas de regime fechado.

\section{A AAD na avaliação do PEESPP pelos participantes: os resultados e a relevância da análise fundamentada em Foucault}

A organização da análise do conteúdo das entrevistas se deu a partir de três eixos emergentes deles próprios, de acordo, também, com o plano de ações para a Educação na Prisão disposto no PEESPP (PARANÁ, 2012; 2015). Por meio dos instrumentos de coleta de dados para a avaliação do Plano, destinados a todos os sujeitos de pesquisa, foi possível apreender a ordem do discurso a respeito de três eixos relevantes acerca do objeto avaliado: o objetivo do PEESPP; a atuação profissional; e a diversidade e o gênero.

Para contextualizar a AAD das entrevistas realizadas junto aos sujeitos que participaram do processo de avaliação do PEESPP (PARANÁ, 2012; 2015) se fez necessária a apresentação perfil socioeducacional dos entrevistados. Este perfil foi delineado por meio dos dados em nível nacional, estadual e institucional de natureza documental, de estatísticas e de questionários. Os dados foram organizados de 
acordo com as atribuições dos sujeitos nas instituições lócus de pesquisa e consistem em informações quantitativas a respeito do gênero que declaram, da faixa etária, da escolaridade, dentre outros pertinentes que serão expostos na análise. Tais dados são relevantes à medida que descrevem quem são os sujeitos que atuam o Plano paranaense nas penitenciárias femininas de regime fechado, bem como indicam a posição de onde falam estes sujeitos.

A respeito do perfil socioeducacional dos sujeitos de pesquisa da instituição que participou de todo o desenvolvimento da investigação, constatou-se: que as internas caracterizam-se como mulheres jovens, de baixa escolaridade, penalizadas por crimes ligados ao tráfico; os professores constituem-se como profissionais graduados, com experiência em docência e em sua maioria realizaram formação stricto sensu, predominantemente na área da Educação de Jovens e Adultos - EJA; os gestores são agentes penitenciários com graduação em Direito; as agentes penitenciárias apresentam uma variedade na formação inicial, não sendo específica para o trabalho no âmbito penitenciário, destacando-se que as contratadas via concurso público realizaram uma formação específica para o exercício da profissão, que não é realizada pelas agentes contratadas por meio de Processo Seletivo Seriado - PSS.

A apreensão do contexto e do perfil socioeducacional dos sujeitos de pesquisa foi imprescindível à avaliação do PEESPP (PARANÁ, 2012; 2015), pois contextualiza a realização de uma avaliação de políticas centrada nos participantes e orientada por/para uma agenda social, possibilitando a compreensão de quem são e de onde falam estes sujeitos.

Munidos do perfil socioeducacional dos sujeitos de pesquisa, na análise dos resultados da avaliação por meio da AAD fundamentada em Michel Foucault (2012) foi possível descrever a ordem dos discursos obtidos pelas entrevistas. $\quad$ A AAD foi organizada em quatro etapas. Na primeira etapa, expõe-se a AAD dos participantes a respeito do objetivo do PEESPP (PARANÁ, 2012; 2015); por meio dos signos 'formação', 'atuação profissional' e 'avaliação' na formação do discurso dos participantes apresenta-se, na segunda etapa, a análise do eixo "atuação profissional"; a terceira etapa desvela a ordem do discurso dos participantes acerca do eixo "diversidade e gênero"; por fim, a quarta etapa contempla, em síntese, uma análise dos principais aspectos do processo de avaliação do PEESPP (PARANÁ, 2012; 2015).

Nas três primeiras etapas foram analisadas as respostas de todos os sujeitos de pesquisa concomitantemente - internas, professores, agentes e gestores - no intuito de apresentar os discursos a respeito dos três eixos de ações do Plano: o objetivo do PEESPP; a atuação profissional; e a diversidade e o gênero. A última seção se detém à análise dos principais aspectos do processo de avaliação do PEESPP (PARANÁ, 2012; 2015) destacando-se as dispersões, as coerências e as ausências na ordem revelada pelos discursos. Esta abordagem possibilitou apontar as perspectivas e os desafios da atuação do Plano no contexto da prática no que diz respeito à atribuição pedagógica da execução penal de promover a inclusão social. 
A respeito dos discursos analisados pela AAD no processo de avaliação do PEESPP (PARANÁ, 2012; 2015), sumariamente, destacam-se: a compreensão da educação enquanto um direito no âmbito prisional; a valorização da educação pelas internas; a falta de formação inicial e continuada aos servidores da instituição penal; a diferença na capacitação dos servidores que ingressam no sistema via concurso público daqueles que ingressam por meio do PSS (Processo Seletivo Seriado); a dificuldade de conciliar uma rotina escolar com uma rotina de segurança; a infraestrutura inadequada; a constatação de especificidades da população penitenciária feminina paranaense; a ausência de enunciados a respeito da desigualdade de gênero; a necessidade do desenvolvimento de processos de avaliação do Plano que sejam capazes de apreender, no contexto da prática, a especificidade institucional e de criar um tempo e um espaço democrático de fala para os sujeitos que atuam a política por meio de seu trabalho.

\section{Considerações finais}

Considerando que a educação para os indivíduos privados da liberdade constitui uma preocupação recente na agenda política no Brasil e, consequentemente, no estado do Paraná, foi pertinente pensar a respeito da atuação dos sujeitos que materializam as ações educacionais do PEESP (PARANÁ, 2012; 2015) desvelada por meio do processo de avaliação. A partir da AAD do conteúdo das entrevistas junto aos sujeitos de pesquisa foi possível a reflexão acerca da questão da educação nas instituições penais femininas do Paraná como tema relevante para o entendimento do desenvolvimento e dos efeitos do PEESP instituído no Brasil em 2011.

Em qualquer perspectiva o objetivo principal de uma avaliação é o de determinar uma medida, o valor ou o mérito daquilo que está sendo avaliado. Entretanto, em uma instituição escolar inserida no âmbito de uma penitenciária, composta por uma diversidade de sujeitos, diversos profissionais, os quais, por meio de suas interações, compõem uma cultura específica que causa impacto no agir, na existência de cada um e nas instituições é imperativo que o processo de avaliação ultrapasse o horizonte de quantificar os resultados.

No desenvolvimento do processo de avaliação apresentado foi necessário um olhar teórico pluralista acerca de seus procedimentos e processos, assim como na análise de seus resultados. Foi realizada uma avaliação baseada na teoria, que articulou e integrou a teoria da Avaliação, a teoria da Política e a teoria das Ciências Sociais, para compreender o geral e o específico e a partir de então produzir saberes e conhecimentos acerca do objeto que é cindido por distintas disciplinas sob vários ângulos (FERNANDES, 2018).

Buscou-se, assim, por meio da pesquisa de avaliação centrada nos participantes, discernir a respeito da qualidade do Plano paranaense ao fundamentar-se em critérios que acolhem a prática e a experiência dos 
sujeitos. Tal posicionamento lhe confere rigor e credibilidade, assim como o uso de seus resultados podem ser socialmente úteis. Nesta perspectiva, a análise arqueológica do discurso (FOUCAULT, 2012) dos resultados da avaliação mostra-se coerente com os objetivos da pesquisa de avaliação de políticas educacionais.

Cientes de que a avaliação tem natureza política, o emprego da análise arqueológica do discurso (FOUCAULT, 2012) demonstrou-se pertinente quando aplicada às pesquisas de avaliação de políticas educacionais centradas nos participantes ao possibilitar a aferição da influência da atuação dos sujeitos na atribuição social da política, bem como de gerar reflexões capazes de aperfeiçoá-la de acordo com as especificidades do contexto e da população as quais se destinam, lhes atribuindo um caráter democrático.

\section{Referências}

AFONSO, Almerindo Janela. Questões, objetos e perspetivas em avaliação. Avaliação, Campinas; Sorocaba, v. 19, n. 2, p. 487-507, jul. 2014.

AFONSO, Almerindo Janela. Avaliar a escola e a gestão escolar: elementos para uma reflexão crítica. In: ESTEBAN, Maria Teresa. (org.). Escola, Currículo e Avaliação. São Paulo: Cortez, 2003.

ARAÚJO, Inês Lacerda. Formação discursiva como conceito chave para a arqueogenealogia de Foucault. Revista Aulas, Campinas, n. 3, p. 01-24, dez./mar. 2007.

AZEVEDO, Rosemeiry Capriata de Souza; RAMOS, Flavia Regina Souza. Arqueologia e genealogia como opções metodológicas de pesquisa na enfermagem. Revista Brasileira de Enfermagem, Brasília, v. 56, n. 3, p. 288-291, mai./jun. 2003.

BALL, Stephen J.; MAGUIRE, Meg; BRAUN, Annette. Como as escolas fazem as políticas: atuação em escolas secundárias. Ponta Grossa: UEPG, 2016.

BRASIL. Decreto $n^{o} 7.626$, de 24 de novembro de 2011. Institui o Plano Estratégico de Educação no âmbito do Sistema Prisional. Disponível em: <http://www.planalto.gov.br/ccivil_03/_Ato20112014/2011/Decreto/D7626.htm>. Acesso em: 15 abr. 2020.

COUTINHO, Raissa Regina Silva; CARLOS, Erenildo João. Currículo, charge e EJA: conexões discursivas. Educação em foco, Belo Horizonte, n. 24, p. 255-275, dez. 2014.

EWALD, François. Foucault, a norma e o direito. Lisboa: Vega, 1993.

FERNANDES, Domingues. Contributos das perspetivas orientadas por/para uma agenda social. IN: FERRÃO, João; PAIXÃO, José Manuel Pinto (org.). Metodologias de avaliação de políticas públicas. Lisboa: Imprensa da Universidade de Lisboa, 2018. p. 49-67.

FERNANDES, Domingues. Acerca da articulação de perspectivas e da construção teórica em avaliação educacional. In: ESTEBAN, Maria Teresa; AFONSO, Almerindo Janela. Olhares e interfaces: reflexões críticas sobre a avaliação. São Paulo: Cortez, 2010.

FOUCAULT, Michel. A arqueologia do saber. Rio de Janeiro: Forense Universitária, 2012.

FOUCAULT, Michel. As palavras e as coisas. São Paulo: Martins Fontes, 1995.

FOUCAULT, Michel. Microfísica do Poder. Rio de Janeiro: Paz e Terra, 2015. 
FOUCAULT, Michel. Vigiar e Punir: nascimento da prisão. Petrópolis: Vozes, 1999.

MACHADO, Roberto. Ciência e Saber - A Trajetória da Arqueologia de Foucault. Rio de Janeiro: Edições Graal, 1981.

MACHADO, Eusébio André. Avaliar é ser sujeito ou sujeitar-se? Elementos para uma genealogia da avaliação. Ramada: Edições Pedago, 2013.

MAINARDES, Jefferson. A pesquisa sobre a organização da escolaridade em ciclos no Brasil (2000-2006): mapeamento e problematizações. Rio de Janeiro, Revista Brasileira de Educação, v. 14, n. 40, p. 7-23, 2009.

MAINARDES, Jefferson. Entrevista com o Professor Stephen J. Ball. Olh@ res, Guarulhos, v. 3, n. 2, p. 161-171, 2015.

MAINARDES, Jefferson. Reflexões sobre o objeto de estudo da política educacional. Laplage em revista, Sorocaba, v. 4, n. 1, p. 186-201, 2018.

MAINARDES, Jefferson; MARCONDES, Maria Inês. Entrevista com o professor Stephen J. Ball: um diálogo sobre Justiça Social, Pesquisa e Política Educacional. Educ. Soc., Campinas, v. 30, n. 106, p. $303-$ 318, jan.-abr. 2009.

PARANÁ. Secretaria de Estado da Educação. Secretaria de Estado da Justiça e Cidadania do PARANÁ. Plano Estadual de Educação no Sistema Prisional do Paraná. Curitiba: DEPEN, 2015.

PARANÁ. Secretaria de Estado da Educação. Secretaria de Estado da Justiça e Cidadania do Paraná. Plano Estadual de Educação no Sistema Prisional do Paraná. Curitiba: DEPEN, 2012.

RODRIGUES, Pedro. As três lógicas da avaliação de dispositivos educativos. In: RODRIGUES, Pedro; ESTRELA, Albano. (org.). Para uma fundamentação da avaliação em educação. Lisboa: Edições Colibri, 1995. p. 93-120.

WORTHEN, Blaine R.; SANDERS, James R.; FITZPATRICK, Jody L. Avaliação de programas: concepções e práticas. São Paulo: Editora Gente, 2004.

YAZBEK, André Constantino. 10 lições sobre Foucault. Petrópolis: Vozes, 2013.

Recebido em: 29/04/2020.

Revisto em: 03/08/2020

Aceito em: 14/08/2020.

Notas

iPós-Doutoranda no Programa de Pós-Graduação em Educação na Universidade Estadual de Ponta Grossa - UEPG. Integrante do Grupo de Estudos e Pesquisas em Políticas Educacionais e Avaliação (GEPPEA). E-mail: bruna.bonatto@hotmail.com ORCID: http://orcid.org/0000-0002-2889-8954

iiDoutora em Educação: Currículo pela PUC-SP. Professora do Programa de Pós-Graduação em Educação UEPG. Coordenadora do Grupo de Pesquisa em Política Educacional e Avaliação - GEPPEA/UEPG. E-mail: marybrandalise@uol.com.br ORCID: https://orcid.org/0000-0003-3674-5314

iii Apesar da compreensão que a genealogia desenvolvida por Michel Foucault não se constitui como algo distinto da arqueologia, "mas sim o desenvolvimento de uma perspectiva diversa ao redor de uma mesma problemática" (YAZBEK, 2013, p. 91), nos 
apropriamos, nesta pesquisa, somente da arqueologia, pois desvelamos o modo como os discursos se investem em diversas instituições, no entanto, sem focar a análise na forma como a ordem de tais discursos indicam formas peculiares do exercício do poder. Para Foucault, a genealogia trata de situar o saber "no âmbito das relações de poder e das lutas políticas próprias da modernidade" (YAZBEK, 2013, p. 91). Sendo assim, a arqueologia é o ponto de partida no qual são desveladas as ordens dos discursos, enquanto a genealogia irá desnudar as estratégias de poder dos discursos indicando a análise histórica de suas condições políticas de existência (YAZBEK, 2013).

iv Para aprofundamento sobre os paradigmas de avaliação consultar: RODRIGUES, P. As três lógicas da avaliação de dispositivos educativos. In: RODRIGUES, P.; ESTRELA, A. (org.). Para uma fundamentação da avaliação em educação. Lisboa, Edições Colibri, 1995. p. 93-120.

${ }^{v} \mathrm{O}$ nível microssociológico abrange o contexto da sala de aula; o mesossociológico corresponde à instituição em todos seus aspectos; o nível megassociológico corresponde aos órgãos internacionais e multilaterais, já o macrossociológico ao âmbito nacional (AFONSO, 2003).

vi Sigla para: sistema de informações estatísticas do sistema penitenciário brasileiro, do governo federal. 